\title{
DE DIFFÉRENCES EN DIFFÉRENDS
}

\section{(réponse à Dominique Guillo)}

Jérôme Michalon, Antoine Doré

Éditions du Croquant | ZZilsel »

$2020 / 2 \mathrm{~N}^{\circ} 7$ | pages 289 à 291

ISSN 2551-8313

Article disponible en ligne à l'adresse :

https://www.cairn.info/revue-zilsel-2020-2-page-289.htm

Distribution électronique Cairn.info pour Éditions du Croquant.

(C) Éditions du Croquant. Tous droits réservés pour tous pays.

La reproduction ou représentation de cet article, notamment par photocopie, n'est autorisée que dans les limites des conditions générales d'utilisation du site ou, le cas échéant, des conditions générales de la licence souscrite par votre établissement. Toute autre reproduction ou représentation, en tout ou partie, sous quelque forme et de quelque manière que ce soit, est interdite sauf accord préalable et écrit de l'éditeur, en dehors des cas prévus par la législation en vigueur en France. Il est précisé que son stockage dans une base de données est également interdit. 


\title{
De différences en différends \\ (réponse à Dominique Guillo)
}

\author{
Jérôme Michalon ${ }^{1} \&$ Antoine Doré ${ }^{2}$
}

Parce que nous travaillons depuis plusieurs années sur les rapports humains-animaux, nous avons été interpellés par les propositions présentées par Dominique Guillo dans Les Fondements oubliés de la culture. Nous avons souhaité en livrer notre lecture, nécessairement partielle, nécessairement située. Nous l'avons fait dans un format contraint (pourtant déjà généreux), qui néanmoins nous paraissait pouvoir permettre à des lecteurs moins familiers de l'objet de situer ces propositions dans un espace intellectuel et académique. Dominique Guillo nous reproche de ne pas avoir évalué sa proposition pour elle-même, de ne pas en avoir formulé une analyse critique «interne ».

De notre point de vue, c'est pourtant ce que nous avons fait. Cette analyse «interne» nous a d'ailleurs davantage conduit à faire l'éloge que la critique d'un programme dont nous soulignons les qualités et la cohérence. La thèse de Dominique Guillo emporte l'adhésion tant qu'elle se déploie, dans une perspective exclusivement épistémologique, en dehors de toute considération institutionnelle, professionnelle et politique relative aux réalités académiques qui structurent les relations entre les sciences de la nature et les sciences sociales examinées dans l'ouvrage. Et le programme proposé fonctionne également tant qu'il fait l'économie d'un positionnement vis-à-vis de certains travaux, antérieurs ou contemporains, visant des objectifs comparables. C'est avec ces éléments «externes» que nous avons souhaité faire discuter la proposition de Dominique Guillo, car il nous semble qu'un compte rendu de lecture est le lieu pour un tel exercice de déplacement.

Noffrant aux lecteurs que la possibilité d'analyser son ouvrage dans une perspective interne, en adoptant le point de vue exclusif de l'auteur, Dominique Guillo impose un déplacement que lui-même se refuse à effectuer. Tant et si bien que l'on se demande

1. UMR Triangle, CNRS, jerome.michalon@ens-lyon.fr.

UMR AGIR, INRAE, antoine.dore @inrae.fr. 
quelle forme de dialogue pourrait bien s'engager ici, puisqu'il faudrait discuter uniquement dans les termes et le format choisis par l'auteur.

Dès lors, nous laissons le soin à d'autres lecteurs de se faire leur propre idée sur les propositions de Dominique Guillo et les réponses qu'il a apportées à nos critiques, dans un débat qui concerne tout autant les spécialistes de l'anthropologie de la nature, ceux de la sociologie de la culture, de l'ethnométhodologie, de l'interactionnisme symbolique, des études de genre, des relations internationales, des classes sociales, de la parenté, ou encore de la famille (pour ne citer que les sciences sociales). Multiplier ces lectures nous paraît la seule solution pour que les propositions de Dominique Guillo puissent atteindre le niveau de généralité auquel elles prétendent et toucher les personnes qu'elle cherche à convaincre - dont nous ne faisons plus partie. 
Fr
ict
ions

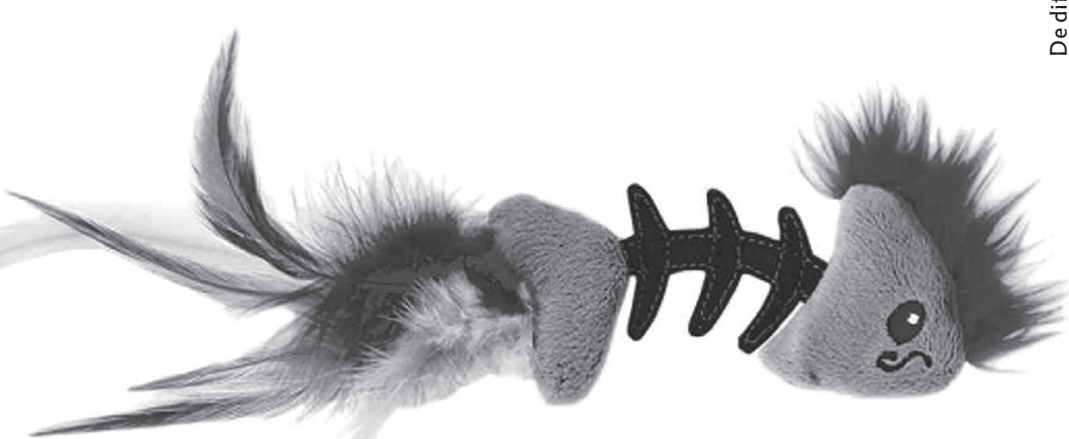

